\title{
Anxiety among dental professionals and its association with their dependency on social media for health information: insights from the COVID-19 pandemic
}

Suhail H. Al-Amad ${ }^{1 *}$ (ID and Amal Hussein ${ }^{2}$

\begin{abstract}
Background: Social media can play a detrimental role during a global health emergency. In this study, we aimed at assessing the impact social media has on the anxiety level of dental healthcare workers (DHCWs) whilst living through the COVID-19 pandemic.

Methods: An online questionnaire was disseminated to a cross-sectional sample of DHCWs from 19 countries using social media platforms. The questionnaire enquired about DHCWs'frequency of using social media and their dependency on health-related information posted on those platforms. Anxiety was measured using General Anxiety Disorder scale (GAD-7).

Results: Four-hundred and three (403) DHCWs completed the online questionnaire. Sixty-eight percent (68\%) frequently use social media for information on COVID-19. The frequency of social media use was higher among younger DHCWs, with shorter clinical experience, and holders of undergraduate qualifications ( $p=0.009, p=0.002$, and $p=0.023$, respectively). Almost one third of DHCWs had moderate to severe anxiety (31.7\%), which was significantly associated with the frequency of social media use $(p=0.016)$. This association was adjusted for age, years of experience and qualification level (OR 1.75; 95\% Cl 1.05-2.93; $p=0.032$ ).

Conclusion: COVID-19 social media infodemic has been adversely impacting the psychological wellbeing of DHCWs. More effective measures are needed to control the quality and spreadability of health information on social media platforms.
\end{abstract}

Keywords: Anxiety, Social media, Dentists

\section{Background}

Since the early days of its identification, COVID-19 has been exponentially trending on social media platforms in an unprecedented manner. Posts on the viral origin, its pathogenesis and transmissibility have flooded social

\footnotetext{
*Correspondence: salamad@sharjah.ac.ae

1 Department of Oral and Craniofacial Health Sciences, Room M28-132, College of Dental Medicine, University of Sharjah, Sharjah, United Arab Emirates

Full list of author information is available at the end of the article
}

media platforms worldwide in a new phenomenon that became known as "infodemic" [1].

The non-specific clinical manifestations, the uncertainties around the viral transmissibility, and the unexplainable wide range of mortality rate [2-4] were among the factors that created knowledge voids, which were quickly filled with often scientifically unfounded information on social media platforms. Unlike previous disease outbreaks, health authorities around the world found themselves compelled to contain a COVID-19 infodemic, along their conventional measures to contain the viral 
pandemic. The easy-to-use technology-driven phenomenon has been causing confusion and uncertainties about COVID-19 pandemic among laypersons and healthcare providers alike.

Dental professionals are at the highest risk of contracting SARS-CoV-2 [5]. This can be attributed to a number of factors: firstly, the ergonomics of dental treatments that require dental healthcare workers (DHCWs) to be at a close proximity to the patient's oral cavity, and for extended periods of time. Secondly, most dental treatments generate large volume of aerosols, which eventually land on the clinician's face, head and neck [6]. Thirdly, saliva has been found to be a rich source of SARS-CoV-2 [7]. And fourthly, viral particles in aerosols were found to remain viable for as long as three hours [8].

Concerns over the psychological wellbeing of healthcare workers and laypersons have been raised [9-12]. Social media infodemic has been linked to depression and anxiety among a large cross-sectional sample of Chinese laypersons [10]. It is not clear if dental professionals, who are at a substantial occupational risk of acquiring COVID-19, are psychologically vulnerable to social media health-related infodemic.

In this study, we aimed at investigating the DHCWs' frequency of social media use, their dependency on the COVID-19 pandemic's health-related information posted on those platforms, and whether this dependency has an association with dental professionals' psychological wellbeing. We hypothesize that a higher frequency of using social media infodemic is associated with a higher anxiety level among DHCWs.

\section{Methods}

This research has been independently reviewed and approved by the University of Sharjah Research Ethics Committee (approval No: REC-20-04-04-02). The said committee works in accordance with the ethical standards of the 1964 Declaration of Helsinki and its later amendments.

\section{Design and sample}

This was a cross-sectional study which was conducted through an online survey. An invitation, which included a link to an online survey, was disseminated by the authors to DHCWs using Emails, WhatsApp and Facebook messaging platforms. Using a snowball sampling method [13], recipients were asked to use their social media networks to forward this invitation to their acquaintances of dental healthcare providers regardless of the country where they are practicing. The targeted population were dentists, dental specialists, dental hygienists, dental nurses and dental technicians who were actively practicing dentistry at the time of the study. Sample size was calculated using the following formula: $\mathrm{N}=\left\{1.96^{2} \times \mathrm{p} \times(1-\mathrm{p})\right\} / \mathrm{ME}^{2}$; where $\mathrm{p}$ was set at $50 \%$ and margin of error at $5 \%$. For a $95 \%$ confidence level, the minimum sample size needed was 385 .

\section{Research tool}

An online questionnaire using Google forms was specifically designed for this study (see Additional file 1). The online questionnaire was pilot tested for clarity and coherence and was modified based on the received feedback. The questionnaire included three sections as follows: Section A enquired about basic demographic variables. Those included the age, sex, years of clinical experience, dental professional category, participants' highest qualification, practice sector and country of practice.

Section B enquired about the frequency of using social media platforms for information on COVID-19 during the previous 14 days. In addition, participants were asked about the frequency of them actively verifying the information that they receive on COVID-19 through social media, and their tendency to visit official websites and read journal articles to learn more about the transmissibility of COVID-19 in dentistry. Answers of this section were registered on a 4- or 5-Likert scale [14].

Finally, section $C$ assessed the level of anxiety using the 7-item Generalized Anxiety Disorders scale (GAD7). Participants were asked to rank their feelings over the past 14 days towards seven anxiety-related statements using a scale that ranged from "not at all" to "nearly every day". Anxiety was categorised into minimal, mild, moderate and severe based on the overall cumulative scores [15].

\section{Statistical analysis}

IBM $^{\circledR}$ SPSS $^{\circledR}$ Statistics (version 26) (IBM Corporation) was used for statistical analysis. Age and clinical experience were categorized into three year-range categories. Values presented in Likert scale were clustered into two or three categories to minimize the number of cells with expected counts less than 5 . Internal consistency reliability of the GAD-7 scale was measured using Cronbach's Alpha. Demographic variables were summarized in frequencies and percentages, and Chisquare test was used to assess the associations between various categorical variables. Binary Logistic Regression models were used to identify predictors of frequent use of social media and moderate/severe anxiety group. p-value was considered significant if $<0.05$. 


\section{Results}

Four-hundred and three (403) dental healthcare workers (DHCWs) participated in this online survey. The mean age of participants was 36.3 years $(\mathrm{SD}=9.7)$, ranging from 23 to 75 years. Females represented $70 \%$ of the sample. The mean duration of clinical experience was 12.3 years $(\mathrm{SD}=9.6)$.

Most of the participating DHCWs were dentists $(n=245(60.8 \%))$, who were less than 40 years of age $(\mathrm{n}=274(69.2 \%))$ and working in the private sector $(\mathrm{n}=179(44.4 \%))$. DHCWs were practicing dentistry in 19 different countries, those were (in alphabetical order): Bahrain, Canada, Egypt, Germany, India, Italy, Jordan,
Kuwait, Malaysia, Oman, Palestine, Poland, Qatar, Saudi Arabia, Syria, Turkey, United Arab Emirates, United Kingdom, United States of America. The majority of participants were working in a Middle Eastern country $(\mathrm{n}=370(91.8 \%))($ Table 1$)$.

All participants in our sample had an account in at least one social media platform. The most commonly used platform was WhatsApp (100\%), followed by Instagram and Facebook (98\% for each), while the least used platform was Tiktok (87\%).

Overall, $68 \%$ of the sample considered themselves to be frequent users of social media for information on COVID-19. WhatsApp and Instagram were the most

Table 1 Description of study sample by socio-demographics characteristics and frequency of using internet resources

\begin{tabular}{|c|c|c|}
\hline Variable & & N (\%) \\
\hline \multirow[t]{3}{*}{ Age } & $=<30$ years & $140(35.4)$ \\
\hline & $31-40$ years & $134(33.8)$ \\
\hline & $>40$ years & $122(30.8)$ \\
\hline \multirow[t]{2}{*}{ Sex } & Males & $120(29.9)$ \\
\hline & Females & $282(70.1)$ \\
\hline \multirow[t]{3}{*}{ Clinical experience } & $1-5$ years & $131(32.9)$ \\
\hline & $6-15$ years & $132(33.2)$ \\
\hline & $>15$ years & $135(34.0)$ \\
\hline \multirow[t]{3}{*}{ Professional category } & Dentist & $245(60.8)$ \\
\hline & Dental specialist & $123(30.5)$ \\
\hline & Dental auxiliary ${ }^{a}$ & $34(8.4)$ \\
\hline \multirow[t]{2}{*}{ Qualification level } & Undergraduate & $218(54.1)$ \\
\hline & Postgraduate & $183(45.4)$ \\
\hline \multirow[t]{4}{*}{ Practice sector } & Private clinic & $179(44.4)$ \\
\hline & Government clinic & $86(21.3)$ \\
\hline & University teaching clinic & $96(23.8)$ \\
\hline & Combined & $36(8.9)$ \\
\hline \multirow[t]{2}{*}{ Jurisdiction region } & Middle East & $370(91.8)$ \\
\hline & Non-Middle East & $29(7.2)$ \\
\hline \multirow[t]{8}{*}{ Dental specialty } & Periodontics & $14(9.3)$ \\
\hline & Prosthodontics & $25(16.6)$ \\
\hline & Restorative dentistry & $11(7.3)$ \\
\hline & Endodontics & $26(17.2)$ \\
\hline & Oral and oral and maxillofacial surgery & $17(11.3)$ \\
\hline & Orthodontics & $29(19.2)$ \\
\hline & Pediatric dentistry & $28(18.5)$ \\
\hline & Others & $1(0.7)$ \\
\hline \multirow[t]{2}{*}{ Frequency of using social media } & Frequently & $274(68.0)$ \\
\hline & Infrequently & $129(32.0)$ \\
\hline \multirow[t]{2}{*}{ Frequency of visiting official public health websites ${ }^{b}$} & Frequently & $316(79.0 \%)$ \\
\hline & Infrequently & $84(21.0 \%)$ \\
\hline \multirow[t]{2}{*}{ Frequency of reading scientific journals } & Frequently & $177(44.7 \%)$ \\
\hline & Infrequently & $219(55.3 \%)$ \\
\hline
\end{tabular}

a Includes dental interns, dental hygienists, dental nurses and dental technicians

${ }^{b}$ World Health Organization, Centre for Disease Control and Prevention, national health jurisdictions 
commonly used platforms for COVID-19 information (41\% and $39.6 \%$, respectively), while the least used ones were Snapchat and Tiktok ( $7.6 \%$ and $1.1 \%$, respectively).

Only $7.4 \%$ of our sample stated that they frequently write-by themselves-posts related to information on COVID-19, while $69.3 \%$ stated that they frequently verify the accuracy of the information that they receive on social media. Around one third of participants (32.3\%) stated that most of the information they received on their social media turned out -at a later time- to be a rumour.

The frequency of utilizing social media for COVID-19 information was significantly associated the DHCWs' age $(p=0.009)$, their years of clinical experience $(p=0.002)$ and their qualification level $(p=0.023)$, whereby older generations and postgraduate degree holders were less frequent users (Fig. 1).

With regards to the perceived reliability, the majority of DHCWs considered the information on COVID-19 which were presented through television news channels and infographic social media posts as reliable $(86.9 \%$ and $56.5 \%$, respectively), while the least reliable source was social media posts consisting of plain text (35.5\%). Regardless of their demographic status, most DHCWs expressed a tendency to frequently verify the information on COVID-19 that they receive on social media before accepting it. However, the ones with the greatest tendency to do so were DHCWs with postgraduate qualifications $(p=0.034)$ (Fig. 2).

Reliability testing of GAD-7 scale revealed a Cronbach's Alpha of 0.937. Almost one third (31.7\%) of DHCWs in our sample scored values that were indicative of moderate or severe anxiety based on the GAD-7 scale. Females and those who are more frequent users of social media showed higher levels of anxiety $(p<0.0005$ and $p=0.016$, respectively) (Table 2 ). The associations between moderate/severe anxiety and female gender (OR 2.01; 95\% CI $1.15-3.49 ; p=0.014)$ and between anxiety and frequency of social media use (OR 1.75; 95\% CI 1.05-2.93; $p=0.032$ ) were independent of age, years of experience, and professional category (Table 3 ).

\section{Discussion}

Today, $51 \%$ of the world population are users of the internet [16]. Information of diverse nature and quality, including health information, are being disseminated between people at a scale that is wider and faster than ever before. In a large study which included 42,087 participants, Din et al. reported that more than half their

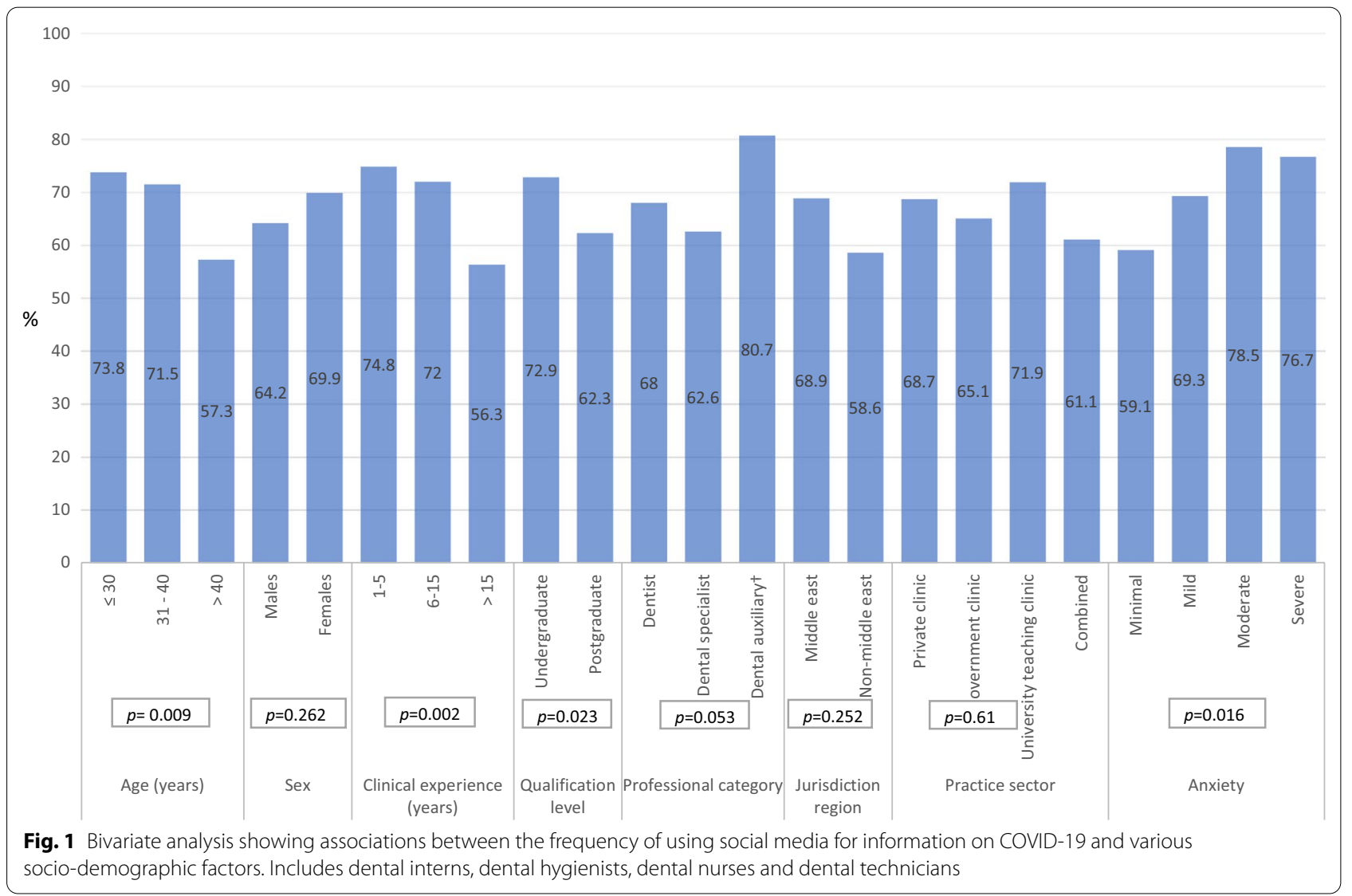




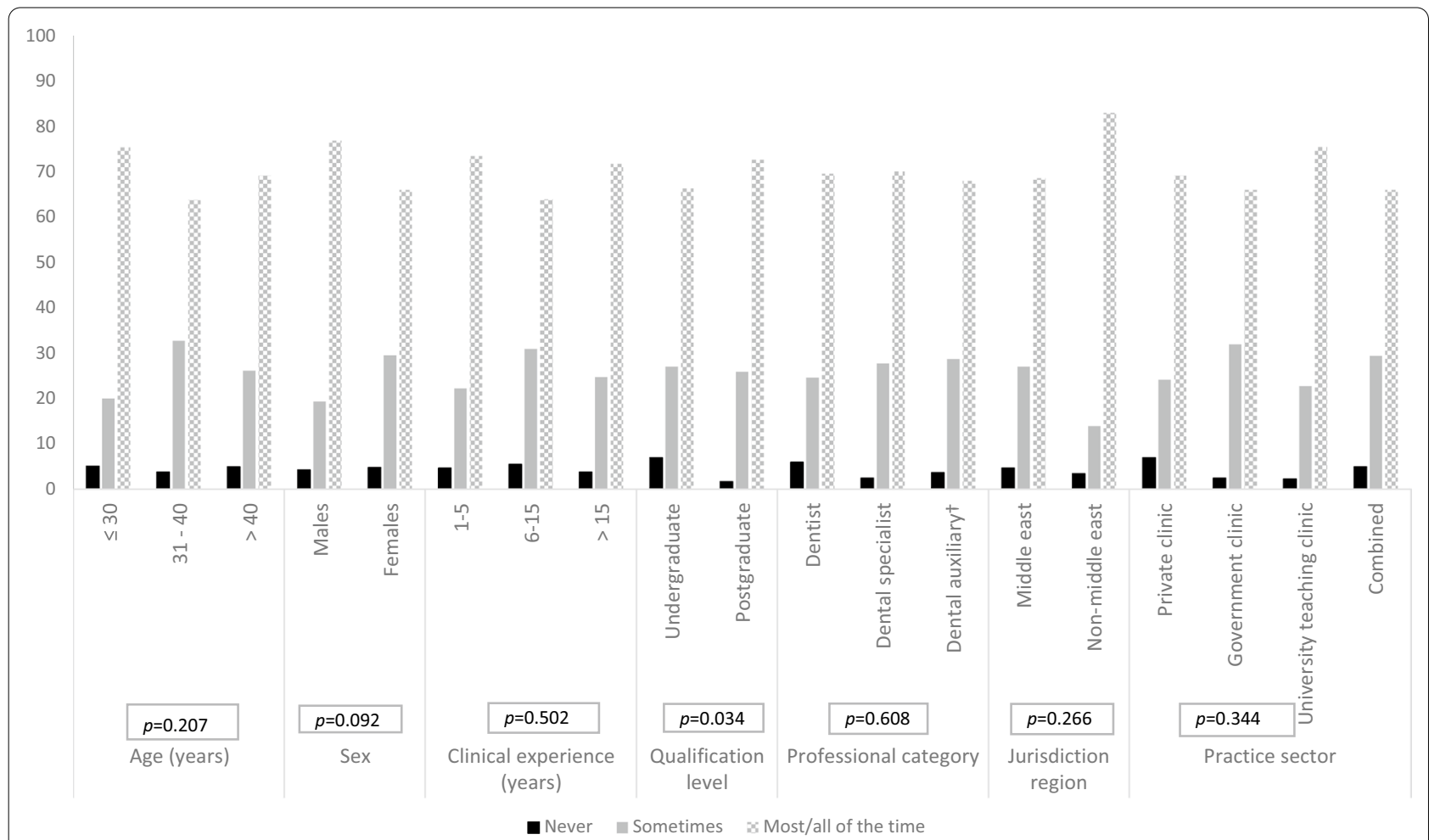

Fig. 2 Bivariate analysis showing associations between the tendency to verify COVID-19 information on social media and various socio-demographic factors. Includes dental interns, dental hygienists, dental nurses and dental technicians

sample used the internet to obtain information related to health, the majority of whom were young, females and of a higher socioeconomic status [17].

Social media platforms are increasingly becoming popular by people of all ages, ethnicities and socioeconomic backgrounds. In the United States-for example-percentage of social media users jumped from 5\% in 2005 to $72 \%$ in 2019 [18]. The International Telecommunication Union estimates that in $2019,46 \%$ of the world's population were active users of social media platforms [16]. Healthcare providers are likewise increasingly engaged in social media use. A recent survey showed that around $88 \%$ of healthcare workers have social media accounts that they use on daily basis $[19,20]$.

The rapid pace of news and uncertainties around the viral genesis, transmissibility and pathogenesis led to information voids which were conveniently and quickly filled with huge amount of social media posts, in a new phenomenon that became known as "infodemic" [1, 19-22]. The rapid spread of information, some of which were later discredited, has floundered people and created a wide-spread anxiety [23, 24].

While most governments have imposed strict measures to reduce the impact of COVID-19 on healthcare infrastructure, the psychological impact of this viral pandemic was not addressed with an equivalent magnitude. As a result, anxiety has been a morbidity rapidly emerging in the background for both laypersons and healthcare professionals, among whom are dental healthcare workers (DHCWs).

Based on the O*NET database, the calculated risk of contracting SARS-CoV-2 is greatest for dentists [5]. With this in consideration, we aimed at investigating the frequency of DHCWs' use of social media for information on COVID-19, and the association between this frequency and DHCWs' psychological wellbeing. Additionally, we aimed at assessing DHCWs' tendency to verify the correctness of COVID-19 information which they receive.

Our results revealed a high prevalence of social media use among DHCWs, whereby all participants have an account in at least one social media platform. More than two-thirds of them frequently rely on social media for information on COVID-19. The frequency of using social media was significantly associated with younger age, shorter clinical experience and lower academic qualifications, which can be explained by the fact that social media and smart hand-held devices are modern-day trends, to which younger generations would be more accustomed to. 
Table 2 Association between general anxiety and various socio-demographic variables

\begin{tabular}{|c|c|c|c|c|c|c|c|}
\hline \multirow[t]{2}{*}{ Variable } & \multirow[t]{2}{*}{ Categories } & \multirow[t]{2}{*}{ Total N (\%) } & \multicolumn{4}{|c|}{ Anxiety groups based on the GAD scores } & \multirow[t]{2}{*}{$P$-value } \\
\hline & & & $\begin{array}{l}\text { Minimal (score } \\
\text { between 0-4) } \\
\mathrm{N}(\%)\end{array}$ & $\begin{array}{l}\text { Mild (score } \\
\text { between 5-9) } \\
N(\%)\end{array}$ & $\begin{array}{l}\text { Moderate (score } \\
\text { between 10-14) } \\
\mathrm{N}(\%)\end{array}$ & $\begin{array}{l}\text { Severe (score } \\
\text { between 15-21) } \\
N(\%)\end{array}$ & \\
\hline \multirow[t]{3}{*}{ Age } & $=<30$ years & $139(35.4)$ & $49(35.3)$ & $48(34.5)$ & $21(15.1)$ & $21(15.1)$ & \multirow[t]{3}{*}{0.096} \\
\hline & $31-40$ years & $135(34.4)$ & $37(27.4)$ & $49(36.3)$ & $20(14.8)$ & $29(21.5)$ & \\
\hline & $>40$ years & $119(30.3)$ & $46(38.7)$ & $40(33.6)$ & $23(19.3)$ & $10(8.4)$ & \\
\hline \multirow[t]{2}{*}{ Sex } & Males & $116(29.5)$ & $58(50.0)$ & $35(30.2)$ & $13(11.2)$ & $10(8.6)$ & \multirow[t]{2}{*}{$<0.0005$} \\
\hline & Females & $277(70.5)$ & $74(26.7)$ & $101(36.5)$ & $52(18.8)$ & $50(18.1)$ & \\
\hline \multirow[t]{3}{*}{ Clinical experience } & $1-5$ years & $129(33.2)$ & $48(37.2)$ & $45(34.9)$ & $20(15.5)$ & $16(12.4)$ & \multirow[t]{3}{*}{0.074} \\
\hline & $6-15$ years & $131(33.7)$ & $35(26.7)$ & $43(32.8)$ & $24(18.3)$ & $29(22.1)$ & \\
\hline & $>15$ years & $129(33.2)$ & $49(38.0)$ & $49(38.0)$ & $18(14.0)$ & $13(10.1)$ & \\
\hline \multirow[t]{2}{*}{ Qualification level } & Undergraduate & $216(55.1)$ & $73(33.8)$ & $76(35.2)$ & $32(14.8)$ & $35(16.2)$ & \multirow[t]{2}{*}{0.750} \\
\hline & Postgraduate & $176(44.9)$ & $58(33.0)$ & $60(34.1)$ & $33(18.8)$ & $25(14.2)$ & \\
\hline \multirow{3}{*}{$\begin{array}{l}\text { Professional cat- } \\
\text { egory }\end{array}$} & Dentist & $218(55.5)$ & $78(35.8)$ & $76(34.9)$ & $33(15.1)$ & $31(14.2)$ & \multirow[t]{3}{*}{0.063} \\
\hline & Dental specialist & $118(30.0)$ & $44(37.3)$ & $42(35.6)$ & $16(13.6)$ & $16(13.6)$ & \\
\hline & Dental auxiliary ${ }^{\mathrm{a}}$ & $57(14.5)$ & $10(17.5)$ & $19(33.3)$ & $15(26.3)$ & $13(22.8)$ & \\
\hline \multirow[t]{2}{*}{ Jurisdiction region } & Middle east & $361(92.6)$ & $120(33.2)$ & $126(34.9)$ & $61(16.9)$ & $54(15.0)$ & \multirow[t]{2}{*}{0.967} \\
\hline & Non-middle east & $29(7.4)$ & $10(34.5)$ & $11(37.9)$ & $4(13.8)$ & $4(13.8)$ & \\
\hline \multirow[t]{4}{*}{ Practice sector } & Private clinic & $175(45.1)$ & $69(39.4)$ & $54(30.9)$ & $33(18.9)$ & 19 (19.9) & \multirow[t]{4}{*}{0.132} \\
\hline & Government clinic & $84(21.6)$ & $27(32.1)$ & $34(40.5)$ & $8(9.5)$ & $15(17.9)$ & \\
\hline & $\begin{array}{l}\text { University teaching } \\
\text { clinic }\end{array}$ & $93(24.0)$ & $26(28.0)$ & $33(35.5)$ & $15(16.1)$ & $19(20.4)$ & \\
\hline & Combined & $36(9.3)$ & $8(22.2)$ & $15(41.7)$ & $7(19.4)$ & $6(16.7)$ & \\
\hline \multirow{2}{*}{$\begin{array}{l}\text { Use of social media } \\
\text { for information on } \\
\text { COVID-19 }\end{array}$} & Infrequently & $124(31.5)$ & $54(43.5)$ & $42(33.9)$ & $14(11.3)$ & $14(11.3)$ & \multirow[t]{2}{*}{0.016} \\
\hline & Frequently & $270(68.5)$ & 78 (28.9) & $95(35.2)$ & $51(18.9)$ & $46(17.0)$ & \\
\hline
\end{tabular}

a Includes dental interns, dental hygienists, dental nurses and dental technicians

While television news channels were perceived as the most reliable source of COVID-19 information, social media posts with infographics had a greater influence on the perceived reliability by comparison with posts consisting of plain text alone. Infographics have been shown to be effective tools in disseminating knowledge, including health information, to audiences from various backgrounds [25-27].

Social media has been playing an increasingly powerful role in disseminating health information. However, when wrong health information was received by desperate persons, serious health consequences ensued [28]. Health information on social media platforms were found to have serious misconceptions [28-30]. Healthcare workers are under the obligation to verify the correctness of health-related information when they receive them. Comfortingly, more than two thirds of our sample indicated that they do verify the accuracy of information which they receive via social media before accepting it. This tendency was significantly associated with the dental professionals who had postgraduate qualifications.
To assess anxiety among DHCWs, we used GAD-7 scale [15], which consists of a simple 7-item questionnaire that assesses the level of anxiety based on a cumulative score. The tool has been validated and found to be a reliable and valid tool to measure anxiety among the general population [31], as well as healthcare providers [32]. In our study, GAD-7 scale showed high reliability among dental practitioners, as indicated by Cronbach's Alpha test (0.937).

Almost one third of our sample gave a cumulative GAD-7 score that ranged from 10 to 21 , indicating a state of moderate to severe anxiety. Females and frequent users of social media were two variables significantly associated with higher anxiety levels $(p<0.0005$ and $p=0.016$, respectively), and this association was independent of age, years of clinical experience and professional category.

Awareness to healthcare workers' mental health has received emphasis in the countries that suffered from COVID-19 at an early stage [9, 11, 12]. Gau et al. reported that $82 \%$ of the general population in China were frequent users of social media and the prevalence 
Table 3 Binary Logistic Regression models identifying predictors of frequent use of social media and Moderate/Severe Anxiety group

\begin{tabular}{|c|c|c|c|c|c|c|}
\hline & \multirow[t]{2}{*}{$\beta$} & \multirow[t]{2}{*}{ se } & \multirow[t]{2}{*}{$p$-value } & \multirow[t]{2}{*}{ Adjusted OR $(\operatorname{Exp} \beta)$} & \multicolumn{2}{|c|}{$\begin{array}{l}\text { 95\% Confidence } \\
\text { Interval }\end{array}$} \\
\hline & & & & & Lower & Upper \\
\hline \multicolumn{7}{|c|}{ Predictors of frequent use of social media } \\
\hline \multicolumn{7}{|l|}{ Age } \\
\hline$\leq 30$ & -0.392 & 0.685 & 0.567 & 0.676 & 0.176 & 2.589 \\
\hline $31-40$ & 0.027 & 0.424 & 0.950 & 1.027 & 0.448 & 2.356 \\
\hline$>40$ & - & - & - & 1 (Reference) & - & - \\
\hline \multicolumn{7}{|l|}{ Level of qualification } \\
\hline Undergraduate & 0.498 & 0.343 & 0.146 & 1.646 & 0.840 & 3.223 \\
\hline Postgraduate & - & - & - & 1 (Reference) & - & - \\
\hline \multicolumn{7}{|c|}{ Experience in dental practice } \\
\hline $1-5$ & 0.934 & 0.686 & 0.173 & 2.545 & 0.663 & 9.766 \\
\hline $6-15$ & 0.376 & 0.435 & 0.388 & 1.457 & 0.621 & 3.421 \\
\hline$>15$ & - & - & - & 1 (Reference) & - & - \\
\hline \multicolumn{7}{|l|}{ Dental professional } \\
\hline Dentist & - & - & - & 1 (Reference) & - & - \\
\hline Dental specialist & 0.354 & 0.352 & 0.314 & 1.425 & 0.715 & 2.840 \\
\hline Dental auxiliary ${ }^{a}$ & 0.302 & 0.388 & 0.437 & 1.353 & 0.632 & 2.896 \\
\hline \multicolumn{7}{|l|}{ Anxiety group } \\
\hline Minimal & - & - & - & 1 (Reference) & - & - \\
\hline Mild & 0.451 & 0.265 & 0.088 & 1.570 & 0.935 & 2.637 \\
\hline Moderate/Severe & 0.836 & 0.295 & 0.005 & 2.307 & 1.295 & 4.110 \\
\hline \multicolumn{7}{|c|}{-2 LogLikelihood $=459.361 x^{2}(\mathrm{df}=9)=19.954 p$ value $=0.018$} \\
\hline \multicolumn{7}{|c|}{ Predictors of moderate/severe anxiety group } \\
\hline \multicolumn{7}{|l|}{ Age } \\
\hline$\leq 30$ & - & - & - & 1 (Reference) & - & - \\
\hline $31-40$ & -0.050 & 0.534 & 0.926 & 0.951 & 0.334 & 2.709 \\
\hline$>40$ & 0.339 & 0.675 & 0.615 & 1.404 & 0.374 & 5.266 \\
\hline \multicolumn{7}{|l|}{ Sex } \\
\hline Male & - & - & - & 1 (Reference) & - & - \\
\hline Female & 0.696 & 0.282 & 0.014 & 2.005 & 1.153 & 3.486 \\
\hline \multicolumn{7}{|c|}{ Experience in dental practice } \\
\hline $1-5$ & - & - & - & 1 (Reference) & - & - \\
\hline $6-15$ & 0.587 & 0.530 & 0.268 & 1.798 & 0.637 & 5.076 \\
\hline$>15$ & -0.101 & 0.687 & 0.883 & 0.904 & 0.235 & 3.476 \\
\hline \multicolumn{7}{|l|}{ Dental professional } \\
\hline Dentist & - & - & - & 1 (Reference) & - & - \\
\hline Dental specialist & -0.019 & 0.289 & 0.948 & 0.981 & 0.557 & 1.727 \\
\hline Dental auxiliary & 0.545 & 0.326 & 0.095 & 1.724 & 0.910 & 3.267 \\
\hline \multicolumn{7}{|l|}{ Use of social media } \\
\hline Infrequently & - & - & - & 1 (Reference) & - & - \\
\hline Frequently & 0.562 & 0.262 & 0.032 & 1.754 & 1.049 & 2.932 \\
\hline \multicolumn{7}{|c|}{-2 LogLikelihood $=450.102 x^{2}(d f=8)=25.303 p$ value $=0.001$} \\
\hline
\end{tabular}

a Includes dental interns, dental hygienists, dental nurses and dental technicians 
rate of anxiety among that population was $22.6 \%$ with a significant association between the two [10].

The difference in the rates of both social media use and anxiety between our study and that of Gau et al. can be attributed to the sample selection and sample size. Whilst Gau et al. conducted their survey on laypersons who were as young as 18 years [10], our sample consisted of older and dentally qualified individuals. Despite the difference in frequencies, both studies present an interesting and significant association between anxiety and the frequency of social media use, which strengthens the inference that social media plays a negative role when it is used as a source of health information, particularly amid a global health emergency.

\section{Conclusion}

In this study, we showed a relatively high prevalence of social media use among DHCWs, which was significantly associated with their anxiety level. The growing emphasis on mental health, particularly among healthcare workers, should take into account its predisposing factors, one of which is modern-day social media infodemic. Despite this finding, the cross-sectional design of our study is not ideal to prove a causal relationship between anxiety and the frequency of social media use, which we observe as a limitation to the generalization of this particular finding.

As dental clinical services gradually resume, we recommend that health jurisdictions pay more attention to the mental wellbeing of those who are most exposed to COVID-19, including DHCWs. This should include regular debriefing and counselling sessions. Access to mental healthcare should also be made available. While some form of filtration of scientific information on social media should be put in place, healthcare providers in general should be discouraged from relying on social media for updates.

\section{Supplementary information}

The online version contains supplementary material available at https://doi. org/10.1186/s40359-020-00509-y contains supplementary material, which is available to authorized users.

Additional file 1.

\section{Abbreviations}

DHCWs: Dental Healthcare Workers; GAD-7: General Anxiety Disorder-7 scale; SARS-CoV-2: Severe Acute Respiratory Syndrome Coronavirus 2.

\section{Acknowledgements}

The authors are grateful for the comments made by Dr Nabeel Al Yateem and Dr Ali Qabbani for their feedback on the questionnaire.

\section{Authors' contributions}

SA prepared the questionnaire, collected the data and wrote the manuscript. AH performed the statistical analysis. Both authors approved the final version of this manuscript.
Funding

This research did not receive funding in any form.

Availability of data and materials

Data is available upon request from the corresponding author.

\section{Ethics approval and consent to participate}

This research has been independently reviewed and approved by the University of Sharjah Research Ethics Committee (approval No: REC-20-04-04-02). The said committee works in accordance with the ethical standards of the 1964 Declaration of Helsinki and its later amendments.

\section{Informed consent}

Information about this research was posted on the first page of the online form, followed by a consent statement. Participants who consented to participate in this research were taken to the questionnaire sections that followed. The completed questionnaires received electronically were considered an implication of the participant's consent to participate in this research. The Information Sheet presented on the first page of the online questionnaire and the Consent process that was implied when participants submitted the online questionnaire were both approved by the University of Sharjah Research Ethics Committee.

\section{Consent for publication}

Not applicable.

\section{Competing interests}

The authors declare that they have no competing interests.

\section{Author details}

${ }^{1}$ Department of Oral and Craniofacial Health Sciences, Room M28-132, College of Dental Medicine, University of Sharjah, Sharjah, United Arab Emirates ${ }^{2}$ Department of Family and Community Medicine and Behavioural Sciences, College of Medicine, University of Sharjah, Sharjah, United Arab Emirates.

Received: 3 September 2020 Accepted: 21 December 2020

Published online: 21 January 2021

\section{References}

1. Zarocostas J. How to fight an infodemic. Lancet. 2020;395:676.

2. Huang C, Wang Y, Li X, Ren L, Zhao J, Hu Y, et al. Clinical features of patients infected with 2019 novel coronavirus in Wuhan, China. Lancet. 2020;395:497-506.

3. Li Q, Guan X, Wu P, Wang X, Zhou L, Tong Y, et al. Early transmission dynamics in Wuhan, China, of novel coronavirus-infected pneumonia. N Engl J Med. 2020;382:1199-207.

4. Zhou P, Yang X, Wang X, Hu B, Zhang L, Zhang W, et al. A pneumonia outbreak associated with a new coronavirus of probable bat origin. Nature. 2020:579:270-3.

5. Gamio L. The workers who face the greatest coronavirus risk. New York: The New York Times; 2020.

6. Al-Amad SH, Awad MA, Edher FM, Shahramian K, Omran TA. The effect of rubber dam on atmospheric bacterial aerosols during restorative dentistry. J Infect Public Health. 2017;10:195-200.

7. To KK, Tsang OT, Leung W, Tam AR, Wu T, Lung DC, et al. Temporal profiles of viral load in posterior oropharyngeal saliva samples and serum antibody responses during infection by SARS-CoV-2: an observational cohort study. Lancet Infect Dis. 2020;20:565-74.

8. van Doremalen N, Bushmaker T, Morris DH, Holbrook MG, Gamble A, Williamson BN, et al. Aerosol and surface stability of SARS-CoV-2 as compared with SARS-CoV-1. N Engl J Med. 2020;382:1564-7.

9. Bao Y, Sun Y, Meng S, Shi J, Lu L. 2019-nCoV epidemic: address mental health care to empower society. Lancet. 2020;395:e37-8.

10. Gao J, Zheng P, Jia Y, Chen H, Mao Y, Chen S, et al. Mental health problems and social media exposure during COVID-19 outbreak. PLoS ONE. 2020:15:e0231924.

11. Kang L, Li Y, Hu S, Chen M, Yang C, Yang BX, et al. The mental health of medical workers in Wuhan, China dealing with the 2019 novel coronavirus. Lancet Psychiatry. 2020;7:e14. 
12. Shigemura J, Ursano RJ, Morganstein JC, Kurosawa M, Benedek DM. Public responses to the novel 2019 coronavirus (2019-nCoV) in Japan: mental health consequences and target populations. Psychiatry Clin Neurosci. 2020;74:281-2.

13. Valerio MA, Rodriguez N, Winkler P, Lopez J, Dennison M, Liang Y, et al. Comparing two sampling methods to engage hard-to-reach communities in research priority setting. BMC Med Res Methodol. 2016;16:146.

14. Vagias WM. Likert-type scale response anchors. Clemson: Clemson International Institute for Tourism \& Research Development, Department of Parks, Recreation and Tourism Management, Clemson University; 2006.

15. Spitzer RL, Kroenke K, Williams JBW, Löwe B. A brief measure for assessing generalized anxiety disorder: the GAD-7. Arch Intern Med. 2006;166:1092-7.

16. International Telecommunication Union, United Nations Educational, Scientific and Cultural Organization. The state of broadband: broadband catalyzing sustainable development. 2019. p. 11.

17. Din HN, McDaniels-Davidson C, Nodora J, Madanat H. Profiles of a health information-seeking population and the current digital divide: crosssectional analysis of the 2015-2016 California Health Interview Survey. J Med Internet Res. 2019:21:e11931.

18. Pew Research Center. Demographics of social media users and adoption in the United States. https://www.pewresearch.org/internet/fact-sheet/ social-media/. Accessed 29 Dec 2020.

19. Brown J, Ryan C, Harris A. How doctors view and use social media: a national survey. J Med Internet Res. 2014;16:e267.

20. Surani Z, Hirani R, Elias A, Quisenberry L, Varon J, Surani S, et al. Social media usage among health care providers. BMC Res Notes. 2017;10:654

21. euronews. Is the new coronavirus 'infodemic'spreading faster than the virus? https://www.euronews.com/2020/03/13/is-the-new-coronaviru s-infodemic-spreading-faster-than-the-virus. Accessed 29 Dec 2020.

22. World Economic Forum. How experts are fighting the coronavirus 'infodemic'. https://www.weforum.org/agenda/2020/03/how-expertsare-fighting-the-coronavirus-infodemic/. Accessed 29 Dec 2020.
23. Shuja KH, Aqeel M, Jaffar A, Ahmed A. COVID-19 pandemic and impending global mental health implications. Psychiatr Danub. 2020;32:32-5.

24. Torales J, O'Higgins M, Castaldelli-Maia JM, Ventriglio A. The outbreak of COVID-19 coronavirus and its impact on global mental health. Int J Soc Psychiatry. 2020;66:317-20.

25. Falk NL. Infographic development by accelerated bachelor of science in nursing students: an innovative technology-based approach to public health education. Nurs Educ Perspect. 2016;37:299-301.

26. Provvidenza CF, Hartman LR, Carmichael J, Reed N. Does a picture speak louder than words? The role of infographics as a concussion education strategy. J Vis Commun Med. 2019;42:102-13.

27. Shanks JD, Izumi B, Sun C, Martin A, Byker Shanks C. Teaching undergraduate students to visualize and communicate public health data with infographics. Front Public Health. 2017;5:315.

28. Oyeyemi SO, Gabarron E, Wynn R. Ebola, Twitter, and misinformation: a dangerous combination? BMJ. 2014;349:96178.

29. Madathil KC, Rivera-Rodriguez AJ, Greenstein JS, Gramopadhye AK. Healthcare information on YouTube: a systematic review. Health Inform J. 2015;21:173-94.

30. Tang L, Bie B, Park S, Zhi D. Social media and outbreaks of emerging infectious diseases: a systematic review of literature. Am J Infect Control. 2018;46:962-72.

31. Löwe B, Decker O, Müller S, Brähler E, Schellberg D, Herzog W, et al. Validation and standardization of the Generalized Anxiety Disorder Screener (GAD-7) in the general population. Med Care. 2008;46:266-74.

32. Alharthy $N$, Alrajeh OA, Almutairi M, Alhajri A. Assessment of anxiety level of emergency health-care workers by generalized anxiety disorder-7 tool. Int J Appl Basic Med Res. 2017;7:150-4.

\section{Publisher's Note}

Springer Nature remains neutral with regard to jurisdictional claims in published maps and institutional affiliations.
Ready to submit your research? Choose BMC and benefit from:

- fast, convenient online submission

- thorough peer review by experienced researchers in your field

- rapid publication on acceptance

- support for research data, including large and complex data types

- gold Open Access which fosters wider collaboration and increased citations

- maximum visibility for your research: over $100 \mathrm{M}$ website views per year

At BMC, research is always in progress.

Learn more biomedcentral.com/submissions 